Editorial

\title{
Introduction: WIR at 30 Topic Forum and AIB Presidential Recognition Award
}

\author{
Jeremy Clegg \\ 1 University of Leeds, UK \\ Keywords: aib presidential recognition award, unctad, world investment report \\ 10.46697/001c.18168
}

\section{AIB Insights}

In this article I introduce AIB Insights' topic forum on the World Investment Report at 30 and the special award session at the Academy of International Business 2020 Annual Meeting that inspired these ensuing articles.

It was with great pleasure that I presented the "AIB Presidential Recognition Award" to The United Nations Conference on Trade \& Development (UNCTAD) during a special session at the Academy of International Business Annual Meeting - AIB 2020. Thus, I am happy to also introduce this topic forum of articles inspired by that session and the 30-year anniversary of the World Investment Report. These articles detail some of the many benefits UNCTAD's World Investment Reports have provided to the International Business community. Anyone working in our subject field, and an innumerable number around the world of those in policy circles, consultants, and practitioners, will already be well aware of the huge value and impact of the Report.

First, let me say something about the award. It is rarely made, and awarded only when there is an outstanding case, as with this year's winner. To underline my point, since the first award in 2006, it has been presented just 4 times, in 2012, 2015 and immediately previously in 2018. This makes UNCTAD only the 5 th recipient in 14 years. Winners of this award are selected by the AIB Executive Board and publicly recognized at the AIB Annual Meeting. From this, I think you can tell that this award is not only very special, but that the awardee must be exceptionally deserving. It is made to recognize: "Distinguished individuals - which includes organizations - for outstanding contributions to the field of International Business or to the mission of AIB." On both counts, UNCTAD's work in producing the annual World Investment Report (WIR) is exemplary.

Dr. James Zhan received the award on behalf of UNCTAD. James has been Director of the Investment \& Enterprise Division at UNCTAD since 2009 and he leads the preparation of WIR, acting, in effect, as its Editor-in-Chief. The citation on the award reads "In recognition of the $30^{\text {th }}$ year of the World Investment Report noting the significance of the Report and its contribution to the field of International Business." By way of background I should mention how the report moves with the times, as well as essentially staying true to its mission. There has been a notable "Paradigm shift" since the global financial crisis and James taking over as Director of the Division - from a focus on "freedom of investment" to "investment for sustainable development". This approach characterizes WIR today.

Lorraine Eden, in her contribution to this issue of AIB Insights, refers to the relationship between AIB and UNCTAD, particularly the Investment \& Enterprise Division. Over the years this has developed from mainly personal ties, by prominent members of AIB, towards a more institutional relationship. I was therefore delighted that, also at the AIB 2020 Annual Meeting, this relationship made a significant step forward, with the establishment of the UNCTAD-AIB Award for Research on Investment and Development, to recognize and reward work on international investment and development by PhD students and early career researchers.

It is thanks to the inspired opportunism of Dr. Karl Sauvant that the World Investment Report has achieved 30 years of exceptional service in bringing accurate data and insightful analysis to the policy, consulting and business communities. To this contribution we can add the academic community, which has relied on WIR to provide a foundation for both theoretical and empirical investigation.

Perhaps I should tell you a little about the genesis of the Report. At the time of the first edition (1991), Karl was Chief of the Research Branch of what was then still the UN Centre on Transnational Corporations. That Branch prepared most of the substantive reports for the annual sessions of the UN Commission on Transnational Corporations, the Centre's legislative oversight body.

I quote from a message to me from Karl: "These were really substantive analyses. However, once the Commission's sessions were over, these reports basically disappeared. I thought that this was a shame, considering that they were quite interesting and had required quite some work to prepare. So, after some discussion with staff, I walked into the office of the Centre's Executive Director - at that time, Peter Hansen, a very open-minded head of the Centre - and suggested that we should adapt a number of the reports and combine them into one sales publication, the World Investment Report 1991: The Triad in Foreign Direct Investment - and he agreed. UN sales publications are - as the name indicates - available to a wider public; we chose the distinct green colour as we wanted the report to stand out among the typically black/dark blue publications of that time. Peter Hansen's Preface stated that"the World Investment Report will provide up-to-date, comprehensive information on an annual basis, and will provide in-depth analyses of a variety of themes, selected for their relevance for policy-making in the field of foreign direct investment".

Karl adds, "The promise on an annual basis was actually a bit ambitious as, before that, the Centre had prepared comprehensive reports only every 5 years". As the $30^{\text {th }}$ anniversary of WIR demonstrates, Karl and his team managed to pull it off! Karl was the leader of the team that prepared WIR from the 1991 edition to the 2005 edition, when he retired from the UN.

Apart from the annual theme for investigation chosen by the WIR team, the Report contains an authoritative statistical part (with a statistical annex), presenting foreign direct investment (FDI) data that have been sourced directly from the member states, normally straight from the official na- 
tional statistical agencies, and harmonized according to rigorous principles. This lends the great authority to the Report's statistics that has, surely, launched a thousand lectures in university courses worldwide. The statistics are taken very seriously indeed by all member states, whose officials and politicians avidly read the Report to see how their economy is performing relative to others. The entire global community of consultants, business representative organisations, and businesses, rely on WIR statistics. Putting the thematic section together with the statistical section means that in the Report, there is truly something for everyone.

While the first World Investment Report was a judicious assemblage of the Commission's internal reports, the way WIR came to be produced in subsequent years could not have contrasted more.

Fast forward around twenty years, and I had the privilege of spending an extended period as a visitor at UNCTAD, during 2008/2009, having, from time to time, visited before and since, when "expert meetings" took place. At that time, Anne Miroux was captaining the WIR team, with a passion that spurred everyone to perform at their best, all of the time. These expert meetings are held when there is a fairly substantial draft available for review to be discussed around the table (hopefully, in the Secretary General's meeting room!). What I had not realised, was how the topic selected each year was hot housed from an idea, and served up on an entirely blank slate. The first such meeting that kickstarted that particular edition made me realise how risk loving the team at WIR actually are. In the early stages, it would be fair to say, one could be wondering whether the endeavour was actually possible. To hit the quality target year after year with new topics is testament to the prodigiously hard work that goes into the production of the Report but, most of all, to the faith that there are indeed pressing issues that cannot be ducked and must be addressed by WIR. As Peter Buckley, in his contribution to this issue of AIB Insights points out, there are a good number of controversial "big question" topics that demand attention; indeed, WIR is spoilt for choice. These big questions have gotten bigger, qualifying for the description "grand challenges". But WIR does not just ask the questions, the burden is upon the team to offer credible, actionable policy recommendations, and this is a challenge in itself to which the Report rises on an annual basis.

In her contribution, Lorraine Eden identifies a list of key emerging issues for future research and the policy agenda of WIR that should keep it busy for well over 10 years. At a deep level, each of these key emerging issues are connected with each other - how do we ensure that, in the future, the benefits of (technological) progress will be equitably divided amongst the world's peoples, and how can International Business help?

The foundational initiative of Dr. Karl Sauvant has truly served us, and the nations of the world magnificently. I hope now, after reading these contributions, you will all agree that the AIB Award to UNCTAD on the occasion of WIR's $30^{\text {th }}$ birthday is not only richly deserved, significant of the importance of the WIR, but also a signal of the evercloser relationship between AIB and UNCTAD that we both envisage. We need more members of our Academy to contribute to UNCTAD, and to its agenda. We have a constellation of experts in AIB. And AIB needs UNCTAD - to help ensure that AIB, as the worldwide academy of the International Business sector, delivers research that has relevance, impact, and genuinely benefits the nations of the world. I sincerely trust that we will have an increasing number of joint forums through which our members can support the admirable and urgent mission of WIR and UNCTAD.

\section{ABOUT THE AUTHOR}

Jeremy Clegg is Jean Monnet Professor of European Integration \& International Business Management at the University of Leeds, United Kingdom. He is an area editor of the Journal of International Business Policy and has served as a member of the editorial review board of the Journal of International Business Studies. His research, employing both quantitative and qualitative methods, encompasses the determinants of foreign direct investment, FDI and regional integration, outward FDI by emerging economies, particularly China, and also human factors within international business. He currently serves as the President of the Academy of International Business (AIB). 